$2016 / 29$

Well-Being, Poverty and Labor Income Taxation : Theory and Application to Europe and the U.S.

François MANIQUeT ANd DiRK NeUmanN

\title{
50 YEARS OF
}

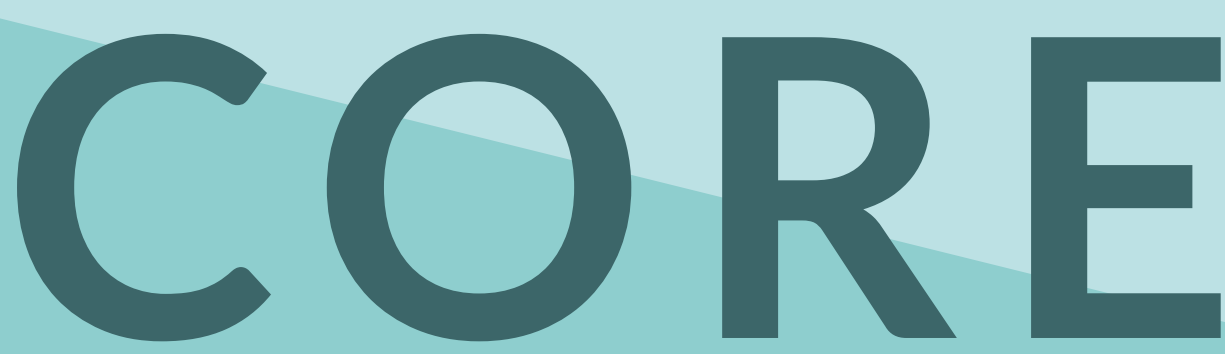

DISCUSSION PAPERS 


\section{CORE}

Voie du Roman Pays 34, L1.03.01

Tel (32 10) 474304

Fax (32 10) 474301

Email: immaq-library@uclouvain.be

http:/ / www.uclouvain.be/en-44508.html 


\title{
Well-Being, Poverty and Labor Income Taxation: Theory and Application to Europe and the U.S.*
}

\author{
François Maniquet ${ }^{\dagger} \quad$ Dirk Neumann ${ }^{\ddagger}$
}

August 2016

\begin{abstract}
In a model in which agents differ in wages and preferences over labor time-consumption bundles, we study labor income tax schemes that alleviate poverty. To avoid conflict with individual well-being, we require redistribution to take place between agents on both sides of the poverty line provided they have the same labor time. This requirement is combined with efficiency and robustness properties. Maximizing the resulting social preferences under incentive compatibility constraints yields the following evaluation criterion: tax schemes should minimize the labor time required to reach the poverty line. We apply this criterion to European countries and the US.
\end{abstract}

JEL Classification: D63, H21, I32.

Keywords: well-being, poverty, labor income taxation.

\footnotetext{
* We thank Craig Brett, Koen Decancq, Marc Fleurbaey, Erwin Ooghe, Stefanie Stantcheva, Matthew Weinzierl, John Weymark, discussants and conference participants in Aix-en-Provence (LAGV), Albadi-Canazei (IT), Antwerp (InGRID), Boston (NTA), Louvain-la-Neuve (CORE@50), Lund (SCW), Mannheim (EEA, ZEW Public Finance), Marseille (CEAFE), as well as seminar participants in Brussels, Leuven and Louvain-la-Neuve for helpful comments. This paper uses the OECD Tax-Benefit Calculator. We thank the OECD for granting us access to the calculator and Sean Gibson for detailed assistance on how to use it. All remaining errors are our own. The research leading to these results has received funding from the European Research Council under the European Union's Seventh Framework Programme (FP7/2007-2013)/ERC grant agreement $\mathrm{n}^{\circ} 269831$.

${ }^{\dagger}$ CORE, Université catholique de Louvain. Email: francois.maniquet@uclouvain.be.

${ }^{\ddagger}$ CORE, Université catholique de Louvain, ZEW and IZA. Email: dirk.neumann@uclouvain.be.
} 


\section{Introduction}

Eradicating poverty is a social objective that many embrace. In developed societies, this objective often requires that all incomes shall be above some threshold, the so-called poverty line. The United States (US) and all European Union (EU) member states, for instance, publish official poverty lines and official poverty rates, defined as the fraction of the population with incomes below the poverty line. ${ }^{1}$ The EU Horizon 2020 objectives include a decrease in the number of people at risk-of-poverty, that is, having a disposable income below their national poverty line.

With an objective of poverty reduction stated in terms of poverty in income, tax-transfer systems are usually evaluated on the basis of the distribution of incomes they generate, and, in particular, on the distribution of incomes below the poverty line. This creates one main difficulty.

Focusing on income disregards the labor time it takes to agents to earn it. However, labor time is also a determinant of well-being, at least if one defines well-being in a consistent way with preference satisfaction, as we do in this paper. $^{2}$ Thus, when increasing income from below to above the poverty line goes together with an increase in the labor time, anti-poverty policies may decrease the well-being of the income-poor. This will be the case if the latter actually prefer to work less and consume less.

This tension between fighting against income poverty and increasing wellbeing (of the poor) is reflected in the optimal income tax literature. Indeed, when it comes to design tax-transfer systems that would optimally alleviate income poverty, it is typically assumed that the objective of the planner consists in leading agents to choose bundles that allow them to consume more than the poverty line, independently of the labor time of those bundles, and, consequently, independently of whether those agents gain or lose, in terms

\footnotetext{
${ }^{1}$ Ideally, a poverty line should be defined in terms of the financial resources available to people for consumption. The official US poverty line was defined in pre-tax income and was criticized for that reason (and many others). See Citro and Michael (1995) and Iceland (2005) for accounts of those criticisms. The Supplemental Poverty Measure, published by the U.S. Census Bureau since 2011, is defined in a much closer way to disposable income. All EU member state's official poverty lines are defined in terms of disposable incomes. Of course, there are many ways of defining disposable income, e.g. as a function of whether in-kind or consumption subsidies are considered as income. See Meyer and Sullivan (2012) for a detailed account of the many issues raised by the definition of the poverty line.

${ }^{2}$ Defining well-being consistently with preferences follows from the assumption that choices reveal what is better for the agent (see Hausman, 2012, for a long discussion of that assumption). This is the assumption we make, and it is necessary to make sense to the Pareto criterion. If one adopts a paternalistic point of view, on the contrary, assuming that poor people make mistakes and are unable to identify what is good for them, then the need to be consistent with what the poor prefer disappears.
} 
of well-being, from the fight against poverty. To phrase it differently, the tax-transfer systems which are proven optimal to alleviate income poverty distort the opportunities offered to poor (that is, typically, low productivity) agents so as to incentivize them to earn more but the loss in opportunities may be accompanied with a loss in well-being. ${ }^{3}$

The following simplified example illustrates this difficulty. Let us assume that two tax-transfer systems are possible. The poverty line is at 11 and the minimum wage is equal to 10 . In the first policy, the poorest agent works halftime, thereby earning a pre-tax income of 5, obtains a transfer of 2 and earns a disposable income of 7 . In the second policy, that agent works full-time, earning 10, and obtains a transfer of 1 , so that her disposable income is equal to 11. Finally, let us assume that the agent strictly prefers to work half-time and get 7 over working full-time and getting 11. The first policy is the one that maximizes the well-being of the poor agent, whereas the second policy is the only one that allows the poor agent to reach the poverty line. This illustrates the tension between alleviating income poverty and increasing the well-being of the poor. Also note that in the example, the transfer needed to implement the first policy is higher than the transfer of the second policy, which means that the latter is less costly than the former in terms of wellbeing of the other, non-poor, agents. The first policy might therefore not be feasible. The cost of redistribution is a key element in optimal income taxation theory, and it will also be a key element in this paper.

That a decrease in income poverty can be accompanied with a decrease in the well-being of the poor has been noted since long (see, for instance, Kanbur, Keen and Tuomala, 1994a and b; Wane, 2001; and, in the case of optimal linear income taxation, Kanbur, Pirttilä, Tuomala and Ylinen, 2015). A similar difficulty also arises when poverty is defined in terms of commodity deprivation instead of lack of income (see Pirttilä and Tuomala, 2004). ${ }^{4}$ Kanbur, Keen and Tuomala (1994b) suggested a solution to that

\footnotetext{
${ }^{3}$ Those distortions lead to opportunity sets that typically fail to satisfy the properties derived by optimal tax theory. Kanbur, Keen and Tuomala (1994a), for instance, conclude that income tax rates should be negative on low incomes when all agents have a positive labor time (and there is no bunching at zero earnings), in contradiction to the classical results (summarized, for instance, in Diamond, 1998). Similarly, Pirttilä and Tuomala (2004) conclude that commodity taxation should not be uniform even if preferences are separable in leisure and goods, against the classical theorem of Atkinson and Stiglitz (1976).

${ }^{4}$ In Besley and Coate (1992), on the contrary, poor agents never suffer from the objective of the planner to decrease poverty. This comes from the fact that labor income taxation is not a tool in the hands of the planner. Instead, she has a fixed budget to allocate and she may require agents to work in exchange of a benefit. Compared with the results above on optimal taxation, this shows that assuming an exogenous budget and
} 
problem, namely to compare the poverty line not with the actual income of an agent but with her equivalent income. The equivalent income, a concept introduced by Samuelson (1974) and Samuelson and Swamy (1974), is the income level that, given some fixed reference wage rate, would leave the agent indifferent to her actual situation. Kanbur, Keen and Tuomala (1994b) do not give any result, however, and they limit themselves at mentioning the arbitrariness of the choice of the reference wage rate.

In this paper, we propose an anti-poverty requirement that does not conflict with individual well-being. Our strategy consists in dropping the classical objective of income poverty reduction and in constructing new social preferences. We do so under the assumption that agents may differ not only in their productivity, like in the papers cited above, but also in their preferences, so that the same opportunity set may lead different agents to different income levels.

The key property we require from social preferences is that a transfer from an agent above the poverty line to another agent below the line be a social improvement only if both agents have the same labor time. This requirement turns out to be compatible with the property of Pareto efficiency. Our first result consists in proving that, together with an auxiliary robustness property, these two properties characterize unique social preferences.

Those social preferences are egalitarian in a specific well-being index representing the preferences of the agents. Namely, the well-being of an agent is computed as the labor time that, associated with a consumption level equal to the poverty line, leaves the agent indifferent to her actual labor timeconsumption bundle. This well-being index does not belong to the family of equivalent incomes and does not require the arbitrary choice of any reference price. On the other hand, it depends on the value of the poverty line, which we take as exogenous. As a result, we make the objective of income poverty reduction compatible with the respect of individual well-being. ${ }^{5}$

Next, we turn to the optimal tax exercise, and we study the consequence of maximizing the social preferences we have characterized under incentive compatibility constraints. These constraints are satisfied when agents choose their labor time given a tax function that determines consumption as a function of earnings. Our main result is the construction of a criterion that can be used to evaluate existing income tax schemes. According to that criterion

disregarding the possible distortions associated with collecting money through taxation assumes away some important incentive issues.

${ }^{5} \mathrm{~A}$ current trend in the literature on the measurement of poverty consists of extending the definition of poverty to other dimensions of life than income. Decancq, Fleurbaey and Maniquet (2015) propose an approach into the latter direction that is also consistent with the respect of individual well-being. 
the pre-tax earning level that is required to reach an after-tax income equal to the poverty line should be minimized.

This criterion allows us to evaluate tax schemes, independently of the distribution of incomes they generate. That is, only the opportunities offered to agents, i.e. their budgets, are considered. Our criterion plays the role of a one number summary of these budgets. The simplicity of the criterion implies that we actually do not need to estimate anything about how individuals react to policy changes to perform welfare analysis. No structural nor reduced-form econometrics is necessary. The sufficient statistics about behavior is entirely contained in the value of our criterion, which can be directly computed from a given tax scheme and poverty line.

We apply the criterion to evaluate the US and European labor income tax schemes. Those schemes are derived based on simulations using the OECD Tax-Benefit Calculator. Our main contribution is to identify the directions of fiscal reforms that would increase social welfare in each of the considered countries. As a by-product of this analysis, we also compare countries and identify those with better tax schemes. It turns out that countries differ widely in the opportunities they offer to poor households, and those performing better according to our criterion are not the countries that transfer the largest benefits to the households where earners do not work at all.

In an online appendix, we additionally study the shape of the optimal tax scheme following from our criterion and we discuss its relationship with tax schemes derived from related social objectives. There, we also identify how each national tax scheme treats different households differently and test the robustness of our applications to changes in the definition of the poverty line, changes in the policies that are simulated and changes due to the heterogeneity of unemployment rates among the countries under analysis.

The paper is organized as follows. In section 2, we present the model. In section 3, we introduce our key property of poverty reduction that does not conflict with individual well-being, and we characterize social preferences. In section 4 , we move to a second-best context and derive an evaluation criterion for tax functions. In section 5, we use this criterion to evaluate US and European labor income tax schemes, under specific assumptions on the poverty line, the relevant social policies and the minimal wage. In section 6 , we give some concluding comments.

\section{The model}

There are two goods, labor, denoted $\ell$, and consumption, denoted $c$. The population contains $n$ agents. That means that there is a finite number of 
agents but we think of that number as a large one, so that the population is diverse in the relevant characteristics. A bundle for agent $i \in\{1, \ldots, n\}$ is a pair $z_{i}=\left(\ell_{i}, c_{i}\right)$, where $\ell_{i}$ is agent $i$ 's labor and $c_{i}$ her good consumption. When we come to the second-best result and the application, the level of consumption will be the after-tax income of the agent. The agents' identical consumption set $X$ is defined by the conditions $0 \leq \ell_{i} \leq 1$ and $c_{i} \geq 0$.

Agents have two characteristics, their preferences over the consumption set and their productivity. For any agent $i \in\{1, \ldots, n\}$, preferences are denoted $R_{i}$, and $z_{i} R_{i} z_{i}^{\prime}$ (resp. $z_{i} P_{i} z_{i}^{\prime}, z_{i} I_{i} z_{i}^{\prime}$ ) means that bundle $z_{i}$ is weakly preferred (resp. strictly preferred, indifferent) to bundle $z_{i}^{\prime}$. We assume that individual preferences are continuous, convex and monotonic. ${ }^{6}$ We further assume that consumption is necessary, in the sense that any bundle with a positive good consumption is always strictly preferred to any bundle with a zero consumption. This assumption will play a role during the construction of the social preferences. We let $\mathcal{R}$ denote this set of preferences.

We allow preferences to differ across agents. Moreover, the heterogeneity is arbitrary, and our results hold true whatever the distribution of preferences in the population.

The marginal productivity of labor is assumed to be fixed, as in a constant returns to scale technology. Agent $i$ 's earning ability is measured by her productivity or wage rate, denoted $w_{i}$, and is measured in consumption units, so that $w_{i} \geq 0$ is agent $i$ 's production when working $\ell_{i}=1$ and, for any $\ell_{i}$, $w_{i} \ell_{i}$ is the agent's pre-tax income (earnings). We assume that $w_{i} \in\left[w_{\min }, \infty\right)$, where $w_{\text {min }}$ stands for the minimum wage rate. We also assume that there are agents in the economy whose wage equals the minimum wage: $w_{i}=w_{m}$ for some $i \in\{1, \ldots, n\}$. Our notion of a minimum wage rate can either refer to a legal minimum wage or to the minimal statistical wage rate.

Figure 1 displays the consumption set, with typical indifference curves, and earnings as a function of labor time. As illustrated in the figure, an agent's consumption $c_{i}$ may differ from her earnings $w_{i} \ell_{i}$. This is a typical consequence of redistribution.

An allocation is a list $z=\left(z_{1}, \ldots, z_{n}\right)$. Social preferences will allow us to compare allocations in terms of fairness principles and efficiency. ${ }^{7}$ Social preferences will be formalized as a complete ordering over all allocations in $X^{n}$, and will be denoted $R$, with asymmetric and symmetric components $P$ and $I$, respectively. In other words, $z R z^{\prime}$ (resp. $z P z^{\prime}, z I z^{\prime}$ ) means that $z$ is at least as good as $z^{\prime}$, (resp. strictly better, equivalent).

\footnotetext{
${ }^{6}$ Preferences are monotonic if $\ell_{i} \leq \ell_{i}^{\prime}$ and $c_{i}>c_{i}^{\prime}$ implies that $\left(\ell_{i}, c_{i}\right) P_{i}\left(\ell_{i}^{\prime}, c_{i}^{\prime}\right)$.

${ }^{7}$ We use 'fairness' in the classical sense of the theory of fair allocation, according to which economic justice is a matter of resource allocation, as opposed to utility level allocation. The poverty-reduction property we define below is consistent with this view.
} 


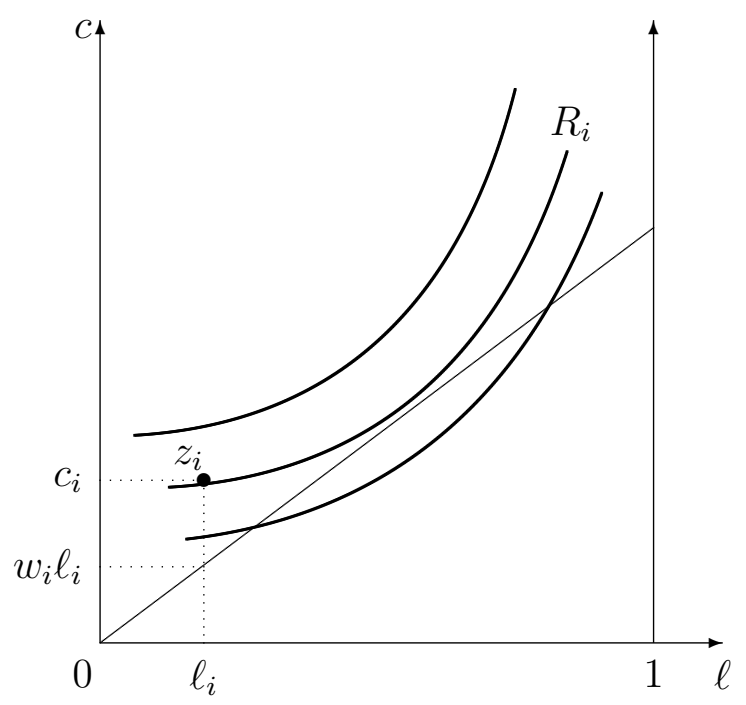

Figure 1: Illustration of the model

Social preferences may depend on the population profile of characteristics $\left(R_{1}, \ldots, R_{n}\right)$ and $\left(w_{1}, \ldots, w_{n}\right)$. However, we may simplify the analysis and consider that the profile of wage rates is fixed. As a result, social preferences $R$ are formally a mapping from the set of population profiles $\mathcal{R}^{n}$ to the set of complete orderings over allocations.

\section{Social preferences}

We assume that there is a poverty line, that is, a consumption level, $p$, with the property that society considers it unacceptable to let people live with less consumption than $p$. This poverty line is fixed. Note that making $p$ depend on $z$, and therefore the income distribution, implies that any policy evaluation would require that the poverty line is recomputed after the policy to evaluate its impact on poverty. This is not what is typically done, and doing it would create the risk of intransitive evaluations. This is why we assume it is exogenous.

We now treat the discussion carried out in the introduction more formally. There are two pitfalls that the objective of poverty reduction should avoid. They are illustrated in figure 2. There are four bundles, $z_{1}, z_{2}, z_{3}$ and $z_{4}$ and two agents, $j$ and $k$ having identical preferences $R_{j}=R_{k}$.

First, let us compare $z_{2}$ and $z_{3}$. We have $c_{2}<p<c_{3}$, so that we could claim that assigning $z_{3}$ to $j$ or $k$ is socially preferable to assigning them $z_{2}$. 
We also have that $z_{2} P_{j} z_{3}$ (and $z_{2} P_{k} z_{3}$ ), though, so a social preference for $z_{3}$ over $z_{2}$ would immediately conflict with individual well-being and, therefore, the Pareto criterion.

Second, let us consider the allocation at which $j$ consumes $z_{1}$ and $k$ consumes $z_{4}$. Again, we might consider that $j$ is poor, because $c_{1}<p$, whereas $k$ is non-poor, because $c_{4}>p$. A transfer of income from $k$ to $j$ could then be thought of as a social improvement, seeming in line with the celebrated Pigou-Dalton progressive transfers in the literature on inequality measurement (see Pigou, 1912, and Dalton, 1920). Contrary to the first pitfall, such a transfer would not conflict with Pareto efficiency because one agent gains and one loses: the Pareto criterion is silent about the ranking of allocations $\left(z_{1}, z_{4}\right)$ and $\left(z_{2}, z_{3}\right)$.

The transfer is not desirable, though, because it amounts to exacerbate inequality in well-being rather than decrease it. Indeed, in well-being terms, agent $k$ at $z_{4}$ is worse-off than agent $j$ at $z_{1}$, in the sense that $z_{4}$ lies on a lower indifference curve than $z_{1}$ (this statement only makes sense because they both have the same preferences) and well-being inequality is larger at $\left(z_{2}, z_{3}\right)$ than at $\left(z_{1}, z_{4}\right)$.

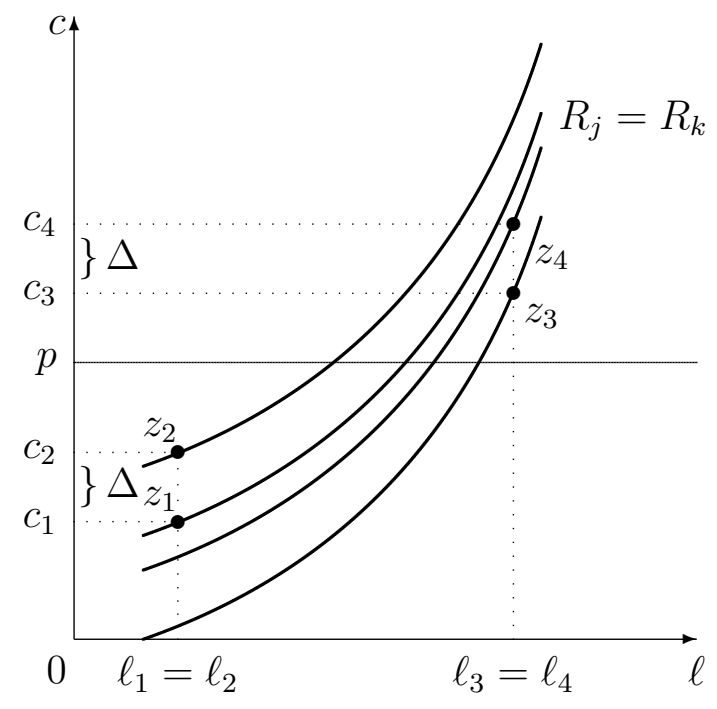

Figure 2: Individual well-being versus the objective of consumption poverty reduction

To avoid these two pitfalls, we look for social preferences that satisfy both the Pareto criterion and the following poverty reduction property: a transfer from a rich to a poor is considered to be a social improvement only under the proviso that the labor time of the two agents is the same. Note that this 
proviso guarantees that both agents agree that the bundle assigned to the agent whose consumption level is above the poverty line is better than the bundle assigned to the agent whose consumption level is below the poverty line. This requirement is illustrated in figure 3 . We state it formally in property 1.

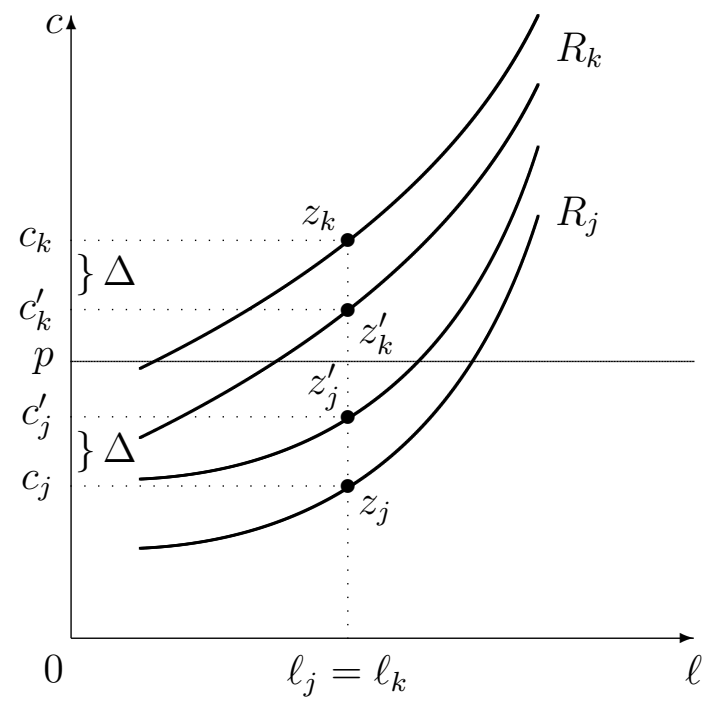

Figure 3: Poverty Reduction: $\left(z_{j}^{\prime}, z_{k}^{\prime}\right)$ is socially preferred to $\left(z_{j}, z_{k}\right)$

\section{Property 1 POVERTY REDUCTION}

For all economies $\left(R_{1}, \ldots, R_{n}\right)$, for all pairs of allocations $z=\left(z_{1}, \ldots, z_{n}\right)$ and $z^{\prime}=\left(z_{1}^{\prime}, \ldots, z_{n}^{\prime}\right)$, if, for two agents $j$ and $k$ and a positive quantity $\Delta$

$$
\begin{aligned}
& \ell_{j}=\ell_{j}^{\prime}=\ell_{k}=\ell_{k}^{\prime}, \\
& c_{j}^{\prime}=c_{j}+\Delta \leq p \leq c_{k}^{\prime}=c_{k}-\Delta,
\end{aligned}
$$

whereas $z_{i}=z_{i}^{\prime}$ for all other agents, then $z^{\prime}$ is socially strictly preferred to $z .^{8}$

Here are three examples of social preferences that satisfy Poverty Reduction. The first example is the social preference relation based on the celebrated income poverty measurement introduced by Foster, Greer and Thorbecke (1984). We denote that social preference by $R^{F G T}$. It is formally

\footnotetext{
${ }^{8}$ In eq. 2, agent $j$, who benefits from the transfer, does not jump over the poverty line as a consequence of the transfer. A stronger version of the property could allow for such a jump, by letting $c_{j}^{\prime} \leq c_{k}^{\prime}, p \leq c_{k}^{\prime}$ but not $c_{j}^{\prime} \leq p$. All the results below would remain true.
} 
defined as follows: For all economies $\left(R_{1}, \ldots, R_{n}\right)$, for all pairs of allocations $z=\left(z_{1}, \ldots, z_{n}\right)$ and $z^{\prime}=\left(z_{1}^{\prime}, \ldots, z_{n}^{\prime}\right), z$ is socially weakly preferred to $z^{\prime}$ if and only if there is less poverty at $z$ than at $z^{\prime}$, that is,

$$
\frac{1}{n} \sum_{i=1}^{n}\left(\frac{\max \left\{0, p-c_{i}\right\}}{p}\right)^{\alpha} \leq \frac{1}{n} \sum_{i=1}^{n}\left(\frac{\max \left\{0, p-c_{i}^{\prime}\right\}}{p}\right)^{\alpha}
$$

Social poverty is defined as the sum of individual poverty. Any agent consuming more than the poverty line has a poverty level equal to 0 . An agent consuming nothing has a poverty level of 1 . The $\alpha$ coefficient stands for the degree of inequality aversion among the poor, which amounts to the priority that is given to people at the very bottom of the consumption spectrum. If $\alpha=0$, all poor agents contribute the same level to global poverty. It amounts to give priority to agents very close to the poverty line, i.e. giving one euro to an agent so close to the poverty line that this agent quits poverty as a consequence of the transfer decreases poverty more than giving one euro to a very poor agent. This is the so-called headcount ratio. If $\alpha=1$, transferring one euro to a poor agent decreases poverty the same way independently of the consumption level of this agent. This is the so-called poverty-gap ratio, measuring the average share of $p$ that needs to be transferred to poor agents to completely alleviate poverty. If $\alpha>1$, transferring one euro to a poor agent decreases poverty more the poorer this agent is. As soon as $\alpha>0$, all social preferences $R^{F G T}$ satisfy Poverty Reduction.

Another example of social preferences that satisfy this property is the generalized utilitarian social welfare function that is often used in optimal taxation theory under the assumption that preferences are quasi-linear (see, for instance, Diamond, 1998). We denote that social preference by $R^{U}$. It is formally defined as follows: for all economies $\left(R_{1}, \ldots, R_{n}\right)$ in which all agents have (possibly different) quasi-linear preferences represented by quasi-linear utility functions $\left(u_{1}, \ldots, u_{n}\right)$, for all pairs of allocations $z=\left(z_{1}, \ldots, z_{n}\right)$ and $z^{\prime}=\left(z_{1}^{\prime}, \ldots, z_{n}^{\prime}\right), z$ is socially weakly preferred to $z^{\prime}$ if and only if

$$
\sum_{i=1}^{n} g\left(u_{i}\left(z_{i}\right)\right) \geq \sum_{i=1}^{n} g\left(u_{i}\left(z_{i}^{\prime}\right)\right)
$$

where $g$ is a strictly concave and strictly increasing real-valued function representing the inequality aversion of the planner. Let us observe that when $\ell_{j}=\ell_{j}^{\prime}=\ell_{k}=\ell_{k}^{\prime}$ and $c_{j}^{\prime}=c_{j}+\Delta<c_{k}^{\prime}=c_{k}-\Delta$, quasi-linearity implies that $u_{j}\left(z_{j}^{\prime}\right)-u_{j}\left(z_{j}\right)=\Delta=u_{k}\left(z_{k}\right)-u_{k}\left(z_{k}^{\prime}\right)$. The fact that $R^{U}$ satisfies Poverty Reduction comes then from the strict concavity of $g$.

A last example is a new social preference relation that we introduce in this paper. It works by applying the leximin aggregator to some particular well-being representation of individual preferences. We denote that social 
preference by $R^{l e x}$. The leximin aggregator works by lexicographically applying the maximin aggregator: first maximize the well-being of the worst-off, in case of a tie, maximize the well-being of the second worst-off, and so on. The new representation of the preferences works as follows. It is a decreasing function of the labor time that leaves an agent indifferent between her current bundle and consuming the poverty line $p$ at that labor time. We denote that labor time $\ell^{p}$. Formally, the well-being of an agent having preferences $R_{i}$ and consuming bundle $z_{i}=\left(\ell_{i}, c_{i}\right)$, denoted $W^{p}\left(z_{i}, R_{i}\right)$, is equal to $-\ell^{p}$ if this agent is indifferent between $z_{i}$ and $\left(\ell^{p}, p\right)$. It is illustrated in figure 4 . Note that, given this construction, $\ell^{p} \in[0,1]$, but the only relevant characteristic of $W^{p}\left(z_{i}, R_{i}\right)$ is to be decreasing in labor time. How decreasing does not matter because we apply the leximin aggregator, which only uses the ordinal information on well-being levels.

There are two cases in which no $\ell^{p}$ satisfying the indifference condition above exists. The first case is when $z_{i} P_{i}(0, p)$, that is, the agent strictly prefers her bundle over not working at all and consuming the poverty line. In this case, there is a consumption level $c$ such that $z_{i} I_{i}(0, c)$. We fix the well-being at such a bundle equal to $c-p$.

The second case is when $(1, p) P_{i} z_{i}$, that is, the current bundle of this agent is so bad that she would prefer to work full-time and consume exactly the poverty line. In this case, there is a consumption level $c$ such that $z_{i} I_{i}(1, c)$. We fix the well-being at such a bundle equal to $c-p-1$.

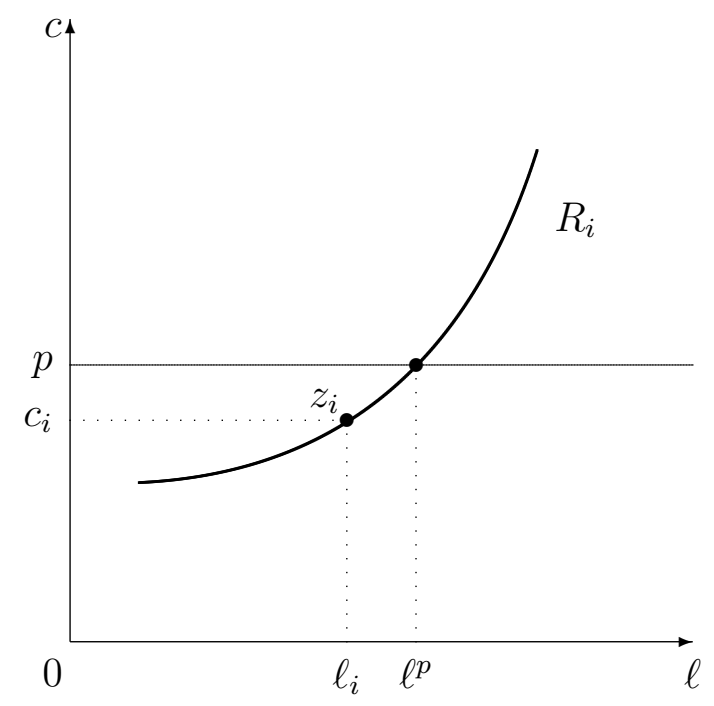

Figure 4: Illustration of the well-being measure $W^{p}: W^{p}\left(z_{i}, R_{i}\right)=-\ell^{p}$.

We now check which social preferences satisfy the other properties we are 
interested in. Our first property is the classical Pareto property, which we now formally define. It guarantees that decreasing the preference satisfaction of an agent will never be a social improvement, even if this decrease goes together with an increase in income above the poverty line.

\section{Property 2 PARETO}

For all economies $\left(R_{1}, \ldots, R_{n}\right)$, for all pairs of allocations $z=\left(z_{1}, \ldots, z_{n}\right)$ and $z^{\prime}=\left(z_{1}^{\prime}, \ldots, z_{n}^{\prime}\right)$, if all agents $i$ weakly prefer $z_{i}$ to $z_{i}^{\prime}$, then $z$ is socially weakly preferred to $z^{\prime}$. If, moreover, $z_{j}$ is strictly preferred to $z_{j}^{\prime}$ for one agent $j$, then $z$ is socially strictly preferred to $z^{\prime}$.

$R^{F G T}$ does not satisfy Pareto. It should not be a surprise, because $R^{F G T}$ only aggregates consumption levels and remains insensitive to increases in labor times.

On the other hand, $R^{U}$ satisfies Pareto, which follows from the fact that these social preferences are directly defined as a function of the utility levels of the agents. These preferences $R^{U}$ are defined for economies in which preferences are quasi-linear. We would like to be more general than that, and be able to define social preferences even when there are income effects. We need to generalize $R^{U}$ to all preferences. Yet, we would like social preferences in non quasi-linear economies to be consistent with that in quasi-linear ones. We capture this requirement with the following property. It requires that social preferences be independent to changes in preferences that do not affect the indifference curves through the bundles we are contemplating. This is a cross-economy robustness property, and it explains why we wanted to define the domain of economies as a function of all possible preference profiles in the economy. This is a way to make our conclusions independent of the precise profile of the preferences in the economy, for instance of the fact that all agents have quasi-linear preferences.

There are many ways in which such independence can be justified. It is a weakening of Arrow's independence property, and a weakening that makes it compatible with fairness properties, as Samuelson (1977) and Pazner (1979) already mentioned. This independence property is also related to incentive compatibility. We postpone that discussion to the next section.

To define that property formally, we need the following terminology. For some preference relation $R_{i} \in \mathcal{R}$ and some bundle $z_{i}$, we let $I\left(z_{i}, R_{i}\right)$ denote the indifference curve at $z_{i}$, that is, the set of all bundles to which this agent is indifferent.

Property 3 IndEPENDENCE

For all pairs of economies $\left(R_{1}, \ldots, R_{n}\right)$ and $\left(R_{1}^{\prime}, \ldots, R_{n}^{\prime}\right)$, and all pairs of allocations $z=\left(z_{1}, \ldots, z_{n}\right)$ and $z^{\prime}=\left(z_{1}^{\prime}, \ldots, z_{n}^{\prime}\right)$, if all agents have the same indif- 
ference curves at $z_{i}$ and $z_{i}^{\prime}$ with preferences $R_{i}$ and $R_{i}^{\prime}$, that is, if $I\left(z_{i}, R_{i}\right)=$ $I\left(z_{i}, R_{i}^{\prime}\right)$ and $I\left(z_{i}^{\prime}, R_{i}\right)=I\left(z_{i}^{\prime}, R_{i}^{\prime}\right)$ for all $i \in\{1, \ldots, n\}$, then the social preference towards $z$ and $z^{\prime}$ is the same in both economies.

$R^{F G T}$ satisfies this property, for all values of $\alpha$. It immediately comes from the fact that $R^{F G T}$ is defined without reference to preferences. It is therefore independent to all changes in preferences, including the ones that leave indifference curves unaffected. Unfortunately, no social preference can generalize $R^{U}$ to non quasi-linear economies so as to satisfy that property. This will come as a corollary of our first result. The social preference relation that we have introduced above, $R^{\text {lex }}$, satisfies all three properties. Moreover, any social preference that satisfies all three properties needs to maximin the well-being measure $W^{p}$. That almost amounts to say that $R^{\text {lex }}$ is the only social preference that satisfies the three properties.

Proposition 1 Social preferences $R^{\text {lex }}$ satisfy Poverty Reduction, Pareto and Independence. Conversely, if social preferences $R$ satisfy Poverty Reduction, Pareto and Independence, then for all economies $\left(R_{1}, \ldots, R_{n}\right)$, for all pairs of allocations $z=\left(z_{1}, \ldots, z_{n}\right)$ and $z^{\prime}=\left(z_{1}^{\prime}, \ldots, z_{n}^{\prime}\right)$, if

$$
\min _{i} W^{p}\left(z_{i}\right)>\min _{i} W^{p}\left(z_{i}^{\prime}\right),
$$

allocation $z$ is socially strictly preferred to $z^{\prime}$.

The formal proof of the proposition is similar to the proof of the main result in Maniquet and Sprumont (2004) in a public-good model. ${ }^{9}$ We provide a complete proof in the online appendix.

Two aspects of proposition 1 are unexpected. First, it tells us that we need to maximize the minimal well-being level, that is, we need to apply an infinite degree of inequality aversion, whereas the property of Poverty Reduction is nothing more than a transfer principle, which is compatible with any degree of inequality aversion. The intuition of this result is not difficult to grasp, though. Let us look at figure 5, a variant of figure 3. The transfer from $k$ to $j$ needs to be declared a social improvement. In terms of well-being, however (that is, in terms of the labor time it takes to reach the poverty line along those indifference curves), we see that receiving $z_{j}^{\prime}-z_{j}$ increases agent $j$ 's well-being by $\ell_{j}^{p}-\ell^{p \prime}$, whereas losing $z_{k}-z_{k}^{\prime}$ decreases agent $k$ 's well-being by $\ell_{k}^{p \prime}-\ell_{k}^{p}$, a much larger amount. One can easily imagine that the well-being increase for agent $j$ is arbitrarily small, whereas the corresponding decrease for agent $k$ is arbitrarily large. An arbitrarily small increase of the poorer

\footnotetext{
${ }^{9}$ The main differences between the two models are that labor time is bounded above and consumption is bounded below in the model of this paper.
} 


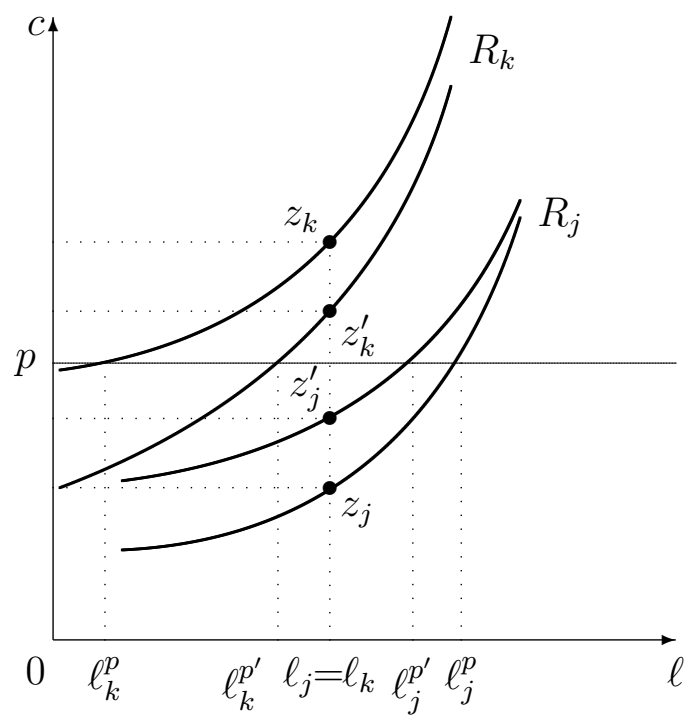

Figure 5: Illustration of why social preferences need to be maximin

agent has to compensate an arbitrarily large decrease for the relatively richer one. This can only be achieved with a maximin objective. ${ }^{10}$

Second, proposition 1 tells us to measure individual well-being according to $W^{p}$, which is expressed in labor time, whereas Poverty Reduction is a property of money transfer. Again, the intuition can be deduced from figure 5. In order to satisfy Poverty Reduction with egalitarian social preferences, one needs to be sure that agent $j$ is considered poorer (that is, at a lower well-being level) at $z_{j}$ than $k$ at $z_{k}$, whatever their preferences $R_{j}$ and $R_{k}$. As suggested in the picture, the indifference curve of these two agents may cross each other. Moreover, they may cross at the vertical of any point either left of $\ell_{j}=\ell_{k}$, or right. Consequently, the only certainty one can have about the indifference curves of agent $j$ at $z_{j}$ and of agent $k$ at $z_{k}$ is that the former crosses the poverty line at a larger labor time than $\ell_{j}=\ell_{k}$, whereas the latter crosses it at a smaller labor time. This is why well-being is measured in labor time along the poverty line, and agent $k$ is claimed to have a larger well-being at $z_{k}$ than agent $j$ at $z_{j}$.

\footnotetext{
${ }^{10}$ Maximin results are frequent in the literature on social preferences based on fairness properties. See Fleurbaey and Maniquet (2011) for a detailed presentation.
} 


\section{Second best}

In the previous section, the objective was to construct a complete ranking of allocations, independently of the information that was needed to rank them. In this section, we introduce the information constraints facing the redistribution designer, that is, we switch to the classical second-best context, whose formalism dates back to Mirrlees (1971). We assume that only earned income $y_{i}=w_{i} \ell_{i}$ is observed, so that redistribution is made via a tax function $\tau\left(y_{i}\right) .{ }^{11}$ This tax is a subsidy when $\tau\left(y_{i}\right)<0$. In this context, meeting the incentive compatibility constraints is equivalent to letting agents choose their labor time in the budget set modified by the tax schedule. Each agent $i$ chooses $\ell_{i}$ knowing that it yields a consumption level $w_{i} \ell_{i}-\tau\left(w_{i} \ell_{i}\right)$.

Of course, the optimal tax functions are to be found among those that allow all agents to consume more than the poverty line, that is, those for which $y-\tau(y) \geq p$ for all $y$, so that, in particular, $-\tau(0) \geq p$. In most economies, though, implementing such tax schemes is budgetary (and, sometimes, politically) too costly. This is why a criterion needs to be developed to evaluate tax functions that do not succeed in bringing everybody above the poverty line. We derive this criterion now.

Given the information available to the tax function designer, the relevant space becomes the earnings-consumption space. Individual preferences in that space are denoted $R_{i}^{*}$, and they are derived from ordinary preferences over labor time-consumption bundles by:

$$
(y, c) R_{i}^{*}\left(y^{\prime}, c^{\prime}\right) \Leftrightarrow\left(\frac{y}{w_{i}}, c\right) R_{i}\left(\frac{y^{\prime}}{w_{i}}, c^{\prime}\right) .
$$

It is a notably difficult task to characterize the optimal tax function when agents differ in wage rates and in preferences (see Lehmann and Jacquet, 2015 , for a recent solution to that problem). We escape the need of such heavy derivations here thanks to the leximin nature of our objective. Indeed, it is sufficient for our purpose to deduce which agent in the population has the lowest well-being index $W^{p}$, or, more precisely, it is sufficient to identify the earning level chosen by the agent with the lowest index. ${ }^{12}$

We derive our main result under the following assumption, which we discuss and justify at the end of the section. It requires that, whatever the tax function we are contemplating, there is at least one agent with the minimum wage rate who chooses the pre-tax income level that is just sufficient to reach

\footnotetext{
${ }^{11}$ See, e.g., Stiglitz (1987), p. 1002-1004, or Boadway and Keen (2000), p. 737-738, for simple presentations of this second-best setting.

${ }^{12} \mathrm{~A}$ similar simplification due to the leximin nature of the social objective is used in Fleurbaey and Maniquet (2006).
} 
a consumption level equal to the poverty line, provided such a pre-tax income level exists. If no such pre-tax income level exists, because after-tax incomes are too low, then there is at least one minimum-wage agent working full-time.

Assumption 1 For each $\tau$, if there exists $y^{p} \leq w_{m}$ such that $y^{p}-\tau\left(y^{p}\right)=p$, then there exists $i \in\{1, \ldots, n\}$ such that $w_{i}=w_{m}$ and $y_{i}=y^{p}$. If $y-\tau(y)<p$ for all $y \leq w_{m}$, then there exists $i \in\{1, \ldots, n\}$ such that $y_{i}=w_{m}$.

The argument leading to the result is illustrated in figure 6. Let us assume that $\tau$ is such that there exists $y^{p} \leq w_{m}$ such that

$$
y^{p}-\tau\left(y^{p}\right)=p .
$$

First, let us restrict our attention to minimum-wage agents, that is, agents with $w_{i}=w_{m}$. In the figure, if $w_{2}=w_{m}$, then $W^{p}\left(z_{2}, R_{2}\right)=-\frac{y^{p}}{w_{m}}$. This type of agent always exists, by assumption 1 . The picture describes the entire indifference curve through bundle $\left(y^{p}, p\right)$, but we need not know the entire shape of the curve. Knowing that this agent has chosen $y^{p}$ is enough to compute $W^{p}\left(z_{2}, R_{2}\right)$. Also, if $w_{1}=w_{m}, W^{p}\left(z_{1}, R_{1}\right)>-\frac{y^{p}}{w_{m}}$. Indeed, choosing an earning level, say $y_{1}$, below $y^{p}$, reveals a preference for $\left(y_{1}, y_{1}-\tau\left(y_{1}\right)\right)$ over $\left(y^{p}, p\right)$. If $w_{3}=w_{m}, W^{p}\left(z_{3}, R_{3}\right)>-\frac{y^{p}}{w_{m}}$ as well, by the same revealed preference argument. That proves that any minimum-wage agent choosing an earning level different from $y^{p}$ has a higher $W^{p}\left(z_{i}, R_{i}\right)$ than agent 2 . This agent has the lowest $W^{p}$-index among the minimum-wage agents.

Second let us consider agents with $w_{i}>w_{m}$. If $w_{2}>w_{m}$, for instance, then agent 2 would need to work less to earn $y^{p}$ and consume $p$ than with a wage equal to $w_{m}$. More specifically, $W^{p}\left(z_{2}, R_{2}\right)=-\frac{y^{p}}{w_{2}}>-\frac{y^{p}}{w_{m}}$. Again, applying the same revealed preference argument as above, if $w_{1}>w_{m}$, $W^{p}\left(z_{1}, R_{1}\right)>-\frac{y^{p}}{w_{1}}>-\frac{y^{p}}{w_{m}}$, and if $w_{3}>w_{m}, W^{p}\left(z_{3}, R_{3}\right)>-\frac{y^{p}}{w_{3}}>-\frac{y^{p}}{w_{m}}$. That proves that the lowest $W^{p}\left(z_{i}, R_{i}\right)$ is the one of the minimum-wage agent earning $y^{p}$.

This reasoning also illustrates that our social preferences do not favor "lazy" agents, which one might expect at first glance. Indeed, any agent like agent 1 in the figure is more averse to work than agent 2, but they have a higher level of well-being, so that agent 2 is given priority by the leximin preferences. The social preferences do not favor hard-working agents, either. Indeed, any agent like agent 3 in the figure is less averse to work than agent 2 , but they have also a higher level of well-being. The only individual preferences that can be claimed to be favored by our social preferences are those of an agent who would always choose the labor time that yields a consumption level equal to the poverty line. 


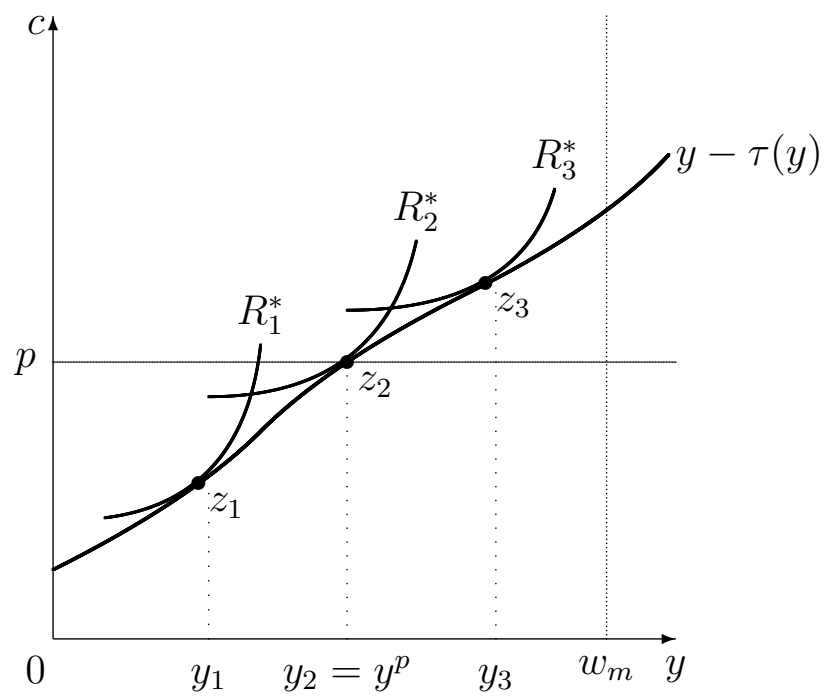

Figure 6: Second-best: who is the worst-off?

Let us assume, now, that no $y^{p}$ satisfying eq. 3 exists. Then, either $-\tau(0)>p$ or $w_{m}-\tau\left(w_{m}\right)<p$. In the former case, the well-being index of an agent who does not work is $-\tau(0)-p>0$. Agents having a strictly positive earning level reveal strict preference of their bundle over $(0,-\tau(0))$ so that their well-being index satisfies $W^{p}\left(z_{i}, R_{i}\right)>-\tau(0)-p$. This means that the lowest well-being index has a strictly positive value so that this allocation is socially preferred to any allocation in which a $y^{p}$ satisfying eq. 3 exists. In the latter case, because assumption 1 guarantees the existence of some agent $i$ such that $w_{i}=w_{m}$ and $y_{i}=w_{m}$, we have $W^{p}\left(z_{i}, R_{i}\right)=w_{m}-\tau\left(w_{m}\right)-p-1<$ -1 , that is, the lowest well-being index has a strictly lower value than -1 , so that this allocation is socially worse than any allocation in which a $y^{p}$ satisfying eq. 3 exists.

We can summarize the result in the following proposition.

Proposition 2 Let $\tau$ and $\tau^{\prime}$ be two tax functions. Under assumption 1, the allocation generated by $\tau$ is socially better than that generated by $\tau^{\prime}$ if one of the following conditions hold:

1. all agents have an after-tax income above the poverty line in the allocation generated by $\tau$ but not by $\tau^{\prime}$,

2. the earning level that is just necessary to obtain an after-tax income equal to the poverty line is lower than the minimum wage and is lower in the allocation generated by $\tau$ than by $\tau^{\prime}$, 
3. the earning level that is just necessary to obtain an after-tax income equal to the poverty line is lower than the minimum wage in the allocation generated by $\tau$ but larger by $\tau^{\prime}$.

Proposition 2 is illustrated in figure 7. Four stylized budget curves are drawn in the earnings-consumption space. Tax function $\tau^{1}$ yields an allocation that is socially better than all the others, according to condition 1 in the proposition. Condition 2 amounts to claiming that the allocation generated by $\tau^{2}$ is socially better than the one generated by $\tau^{3}$. Condition 3 amounts to claiming that $\tau^{4}$ is the worst tax function among the four represented in the figure.

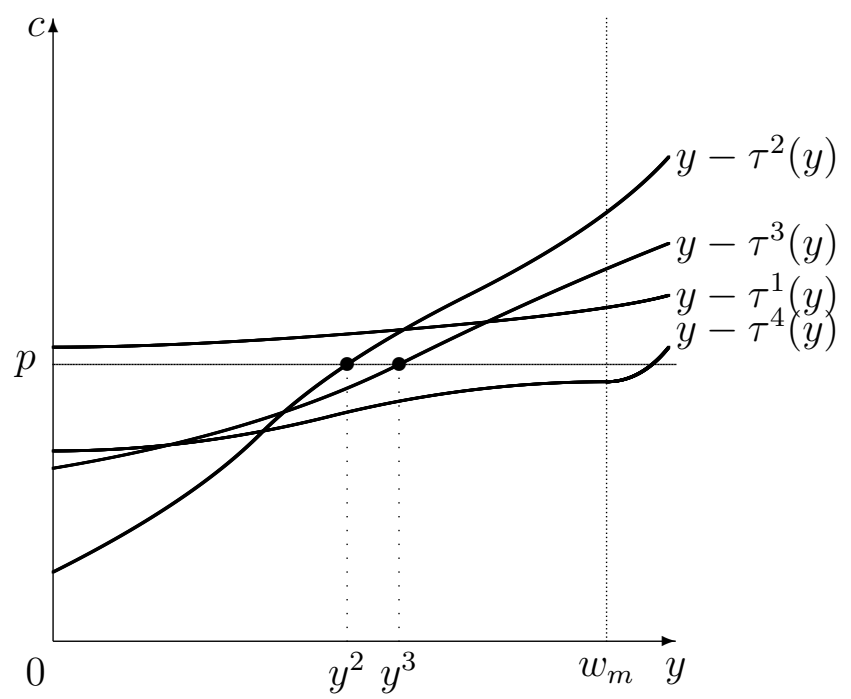

Figure 7: Illustration of proposition 2

We have proven that the evaluation criterion for tax functions is the pretax income that is just necessary to reach a consumption level equal to the poverty line, because it reveals the labor time it takes to the minimum-wage agents to reach that level. Consequently, a reform of a tax function aiming at increasing social welfare should decrease the amount of taxes (or typically, increase the amount of subsidies) at this precise pre-tax income level. In order to apply the criterion to the evaluation of existing tax schemes, the only statistics that we need to measure is the pre-tax level that is necessary to reach a consumption level equal to the poverty line. That means that nothing needs to be estimated in terms of individual responses to changes in the tax scheme. This simplicity is quite striking when compared with the typical estimations of behavioral parameters that are needed to apply optimal 
tax formulas derived from the maximization of general social preferences (see, for instance, Chetty, 2009; Saez and Stantcheva, 2016; Jacquet and Lehmann, 2015).

We conclude the second-best analysis with two comments, one on our third property, Independence, and one on assumption 1. First, the well-being index that proposition 1 teaches us to use gives us a numerical representation of preferences that only depends on the indifference curve through the bundle we are contemplating. This immediately follows from Independence, which prevents social judgments about bundle $z_{i}$ to depend on preference information outside that indifference curve. This is the reason why we succeed in deriving proposition 2 . Indeed, the only fact that one agent, agent 2 in the reasoning above, chooses to earn $y^{p}$, reveals enough of her well-being index to help us conclude that she is the worst-off. With social preferences violating Independence, we might have had first to check for preferences of agent 2 over bundles not contained in her indifference curve through her chosen bundle and such a check would have typically been impossible to do, because we cannot collect more information than agent 2's best bundle in her budget set. It would not have been possible to derive a second-best criterion corresponding to social preferences requiring more information than indifference curves through the contemplated bundles. The surprise, actually, comes from the fact that it is possible to derive a criterion from $R^{\text {lex }}$. Indeed, agent 2's choice does even not reveal her entire indifference curve. Fortunately, the local information it reveals is sufficient to make the criterion work.

Second, proposition 2 is derived under an unusual assumption that bears on both the types of the agents and the shape of the tax function. We discuss and justify it now. Let us assume that, contrary to the assumption, no minimum-wage agent chooses earning level $y^{p}$. There can be two cases. Either no agent chooses $y^{p}$, or only higher-wage agents choose it.

In the first case, the part of the budget curve around $y^{p}$ is irrelevant. That means that $\tau$ can be adjusted, decreased, until it becomes relevant, that is, until some agents find it interesting to earn pre-tax incomes around $y^{p}$. This exercise can actually be done until all points of $\tau$ are relevant, that is, until it coincides with the lower envelope of agents' indifference curves through their chosen bundles. After $\tau$ is adjusted, either the assumption is satisfied, or we have reached the second case.

That is, let us assume that all agents earning $y^{p}$ have a higher wage than $w_{m}$. In theory, it can be justified to increase the tax at $y^{p}$ to collect more money and redistribute it towards worse-off agents. In practice, though, this is irrelevant, because it amounts to claim that the tax rate at some $y<w_{m}$ should be computed by the fiscal authority on the basis that this authority is certain that all agents earning that amount are high-skill agents. It does not 
sound like a plausible justification, because the typical information a fiscal authority has about the distribution of wages and earnings does not allow it to exclude the possibility that agents with a given wage work a given fraction of their time. We view assumption 1, actually, as reflecting the imprecision of the available information, with the consequence that the tax designer cannot exclude the existence of an agent having the characteristics mentioned in the formal statement above.

\section{Application}

We now turn to the application of the criterion developed in section 4, i.e. its use to evaluate existing tax schemes. For this exercise we need to draw the actual budgets that agents face. Given that the tax function typically depends on the composition of the households, we partition the population into household types. ${ }^{13}$ Budgets are drawn for these household types using the OECD Tax-Benefit Calculator which takes account of all relevant regulatory aspects that transform pre-tax incomes into after-tax incomes in OECD countries. ${ }^{14}$

We evaluate the ability of tax-transfer policies to alleviate poverty given official poverty lines, the official notion of disposable income and the legal minimum wage. As a result, we restrict our sample to the EU15 countries that have a legal minimum wage ${ }^{15}$ and the United States (US) ${ }^{16}$ and calculate budgets for tax-transfer rules of 2013. Precisely, the tax-transfer policies that are taken into account are income support and social assistance (SA), ${ }^{17}$ family and child benefits (FB), housing benefits (HB), in-work benefits (IW), labor income taxes (IT) and social insurance contributions (SC). We assume that policies implemented to fight against non take-up and fiscal evasion

\footnotetext{
${ }^{13}$ If we assume households instead of single individuals to be the decision makers, our theory can be readily applied to this context. This implies the adoption of the unitary model in the case of couple households.

${ }^{14}$ The calculator and the detailed policies modeled are documented on the website of the OECD Tax-Benefit Calculator as well as in the country chapters of the OECD series "Benefits and Wages": www.oecd.org/els/benefits-and-wages-models.htm, www. oecd.org/els/soc/benefits-and-wages-country-specific-information.htm.

${ }^{15}$ Belgium (BE), France (FR), Germany (GE), Greece (GR), Ireland (IR), Luxemburg (LU), the Netherlands (NL), Portugal (PT), Spain (SP), the United Kingdom (UK).

${ }^{16}$ Tax-transfer systems in the US are largely state specific. The OECD calculator uses the tax-transfer system of Michigan, a typical manufacturing region, to represent the US.

${ }^{17}$ Unemployment insurance benefits are not taken into account as they are typically conditional on past labor force participation and social contributions. As a result, young or long-term unemployed people typically do not benefit from it. Unemployment assistance benefits, which are not based on previous contributions, are considered to be part of SA.
} 
are distinct from the definition of the tax-transfer system itself and we thus abstract from the latter phenomena here. We come back to this in section 6 .

Disposable income is derived on the basis of the labor income that is earned when increasing hours worked from zero to full-time. The wage earned is the legal monthly minimum wage in each country in 2013, as reported by EUROSTAT $^{18}$ (see fifth column in table 1). ${ }^{19}$

In the Europe 2020 strategy, ${ }^{20}$ the European member states have agreed to use $60 \%$ of national median equivalized disposable income as the at-riskof-poverty indicator. We thus use this poverty threshold for the European countries in our analysis, as reported by EUROSTAT. ${ }^{21}$ For the US, we rely on the Supplemental Poverty Measure reported by the U.S. Census Bureau. ${ }^{22}$

Results are presented for single-parent households with two children (aged 10 and 12). The reason is that those households are known to be at high risk of poverty. ${ }^{23}$

The details about the methodology are presented in the online appendix. There, we also identify how each national tax scheme treats different households differently and test the robustness of our application to changes in the definition of the poverty line, changes in the policies that are simulated and changes due to the heterogeneity of unemployment rates among the countries under analysis. Finally, we systematically provide the full set of results of our application, that is for all countries and all household types.

\subsection{Measuring and decomposing social welfare}

The first column of table 1 shows $W_{\min }^{p}$, the measure of social welfare according to $R^{\text {lex }}$, in percentage of a full-time job, for single-parent households with two children. For instance, the worst-off households of that type in the US are those who work $51.13 \%$ of their time (where $100 \%$ of one's time means a full-time job). The percentage of labor time needed to reach the poverty line varies from $0 \%$ in Germany, Ireland, the Netherlands and the UK, where even those who do not work have the opportunity to get out of

\footnotetext{
${ }^{18}$ ec . europa. eu/eurostat/web/products-datasets/-/tps00155.

${ }^{19}$ Germany introduced a legal minimum wage in 2015. The wage for Germany is this minimum wage deflated to 2013.

${ }^{20}$ ec.europa.eu/eurostat/statistics-explained/index.php/Europe_2020_headline -indicators.

${ }^{21}$ ec. europa.eu/eurostat/web/products-datasets/-/ilc_di04.

${ }^{22}$ Detailed information about this measure and its derivation for 2013 can be found in Short (2014). A historical comparison of official poverty measures used in the US up to the Supplemental Poverty Measure can be found in Meyer and Sullivan (2012).

${ }^{23}$ See, e.g., ec.europa.eu/eurostat/web/products-datasets/-/ilc_peps03.
} 


\begin{tabular}{lccccccc}
\hline \hline & $-W_{\min }^{p}$ & $-W_{\min }^{p} w_{m}$ & $b$ & $\tau$ & $w_{m}$ & $p$ & $\frac{w_{m}}{p}$ \\
\hline $\mathrm{US}$ & 51.13 & 646.72 & $1,018.28$ & 7.02 & $1,264.96$ & $1,739.71$ & 72.71 \\
$\mathrm{BE}$ & 97.95 & $1,953.65$ & $2,128.09$ & 84.42 & $1,994.57$ & $2,284.44$ & 87.31 \\
$\mathrm{FR}$ & 97.00 & $1,842.41$ & $1,571.74$ & 62.58 & $1,899.48$ & $2,225.79$ & 85.34 \\
$\mathrm{GE}$ & 0.00 & 0.00 & $2,116.80$ & 68.25 & $1,938.84$ & $2,076.62$ & 93.37 \\
$\mathrm{GR}$ & 107.09 & 972.47 & 182.87 & 12.58 & 908.10 & 890.04 & 102.03 \\
$\mathrm{IR}$ & 0.00 & 0.00 & $2,353.30$ & 75.37 & $1,941.48$ & $2,025.62$ & 95.85 \\
$\mathrm{LU}$ & 15.95 & 397.07 & $3,195.76$ & 84.76 & $2,489.11$ & $3,538.16$ & 70.35 \\
$\mathrm{NL}$ & 0.00 & 0.00 & $2,321.35$ & 74.69 & $1,951.51$ & $2,213.57$ & 88.16 \\
$\mathrm{PT}$ & 112.99 & 849.07 & 495.40 & 61.36 & 751.48 & 868.79 & 86.50 \\
$\mathrm{SP}$ & 146.97 & $1,469.54$ & 771.64 & 70.32 & 999.86 & $1,436.79$ & 69.59 \\
$\mathrm{UK}$ & 0.00 & 0.00 & $2,510.71$ & 77.68 & $1,659.93$ & $1,986.20$ & 83.57 \\
\hline \hline
\end{tabular}

Note: $-W_{\min }^{p}$ in $\%$ of full-time. $\frac{w_{m}}{p}$ in $\%$. All other values in monthly USD. Germany introduced a legal minimum wage in 2015. $w_{m}$ for Germany is this minimum wage deflated to 2013 .

Table 1: Social welfare and its decomposition for single households with two children

poverty, to countries in which it is impossible for low-skill households to get out of poverty even by working full-time, namely Greece, Portugal and Spain. The second column shows the pre-tax income corresponding to this measure, $-W_{\min }^{p} w_{m}$. For instance, the worst-off in the US, according to $R^{l e x}$, are those who work at the minimum wage and earn 646.72 USD. This is the main result delivered by our approach: if a policy-maker in the US is interested in the normative property of Poverty Reduction defined above, she should modify the tax-transfer system in order to increase, in the limit of what is feasible, the disposable income of those earning 646.72 USD resp. decrease the pre-tax income necessary to reach the poverty line. Clearly, this objective can be reached through different policy tools. Besides classical tax-transfer instruments, also the legal minimum wage could be increased to this end.

The next columns of the tables decompose that key statistic into the three policy parameters that determine it. The first one is the basic income, $b$, that is, the disposable income of those who do not earn anything. It gives us the level of the opportunity set available to those who do not work. The second one is the rate $\tau$ at which low incomes are effectively taxed. That is, given any additional dollar earned, how much of it is taken away by the tax-transfer system, on average, below the minimum wage. This tool gives us a summary of the shape of the opportunity set of low-skill households, that is, of how their labor is rewarded. The third one is the minimum wage 
itself, $w_{m}$, but its effect on our key statistic is best seen when it is expressed as a percentage of the poverty line, $\frac{w_{m}}{p}$, which is done in the last column. It shows that, except in Greece, no household of the type we are looking at could reach the poverty line without benefits.

If the marginal tax rate were constant over low incomes at $\tau$, then our measure of social welfare would satisfy the equation $p=b+W_{\min }^{p} w_{m}(1-\tau)$, which gives us

$$
W_{\min }^{p}=\frac{p-b}{w_{m}(1-\tau)},
$$

illustrating how the combination of the three policy parameters, $b, \tau$ and $w_{m}$ determine social welfare and how they can be used to increase it. Social assistance, family benefits and housing benefits typically determine $b$. How these benefits fade out when gross income increases, in-work transfers, income tax and social security payments together determine $\tau$. Finally, $w_{m}$ is a direct policy instrument.

\subsection{Extended cross-country comparison}

In figure 8, we draw the entire budget curves for single-parent households with two children for all countries over the relevant income span. Countryspecific budget curves are made comparable by rescaling the axes such that all minimum wages (resp. poverty lines) correspond to coordinate 1 along the horizontal (resp. vertical) axis.

The figure clearly shows the large variety of policies across countries. The budget curves in Belgium, Luxemburg, the Netherlands and Spain are characterized by a $100 \%$ tax rate on the lowest incomes, sometimes after a small interval of lower tax rates. This $100 \%$ tax rate is produced by the one-dollar decrease in social assistance following any one-dollar increase in gross income over that interval. The budget curves in Germany, France and Portugal are strictly increasing, but at a slow rate, illustrating the way social assistance and, in the case of France and Germany, housing benefits, fade out as gross income increases. The budget curves in Ireland, the UK and the US are steeper, illustrating the in-work benefits existing in these three countries, even if its implementation gives a much smoother budget curve in the US than in the other two countries. The budget curve in Greece is characterized by the disappearance of basically all social assistance programs, except modest family benefits, coupled with very low income tax rates.

The most important lesson to draw from the figure is that there is no clear relationship between the set of policies that are implemented and our measure of social welfare. Germany, Ireland, the Netherlands and the UK are doing the best in terms of $W_{\min }^{p}$, and they offer budgets of very different 
Budget schemes - single with two children (2013)
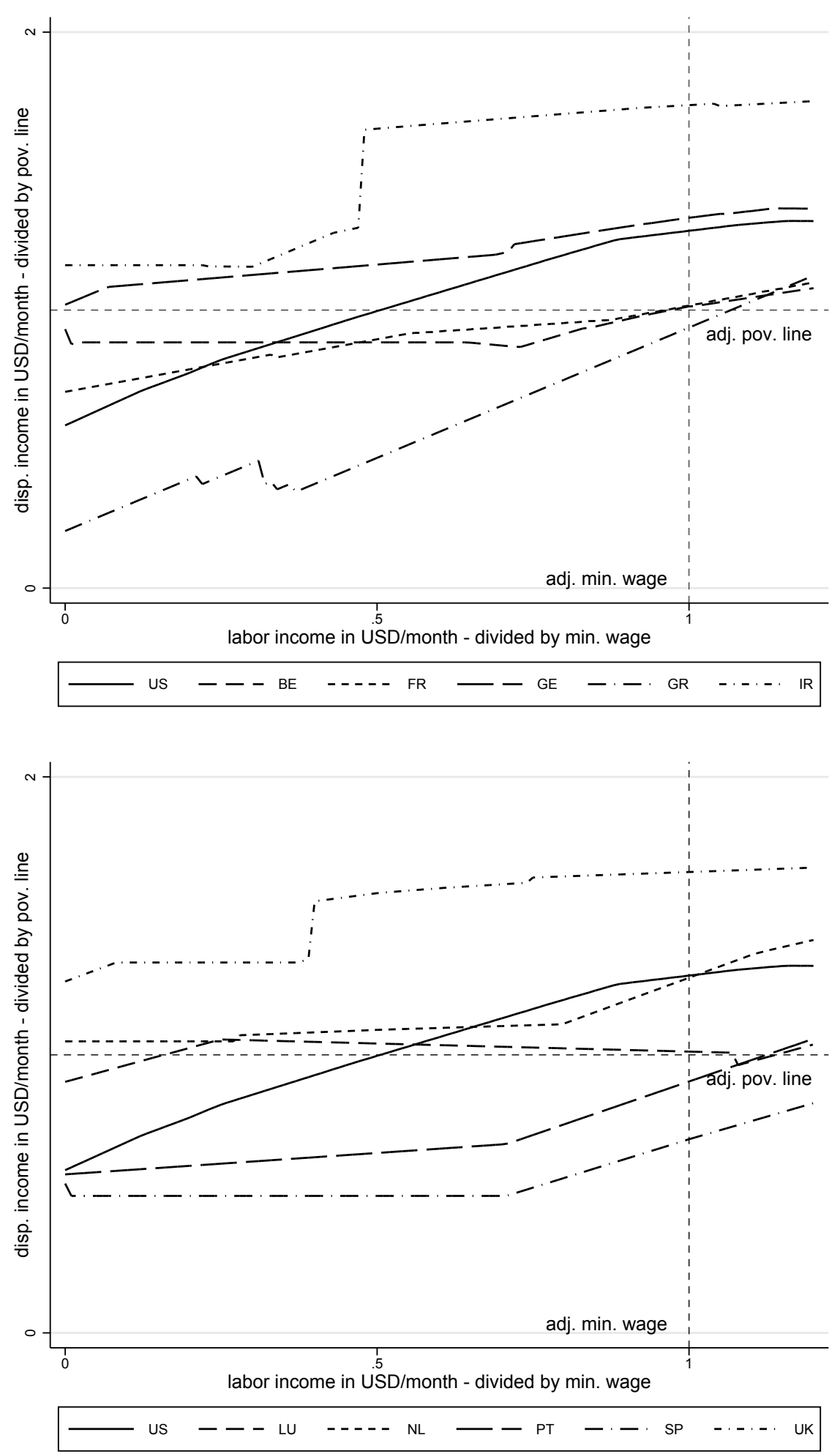

Figure 8: Cross-country comparison of entire budget curves for single households with two children 
shapes. The basic income is much lower in the US than in France or Belgium, but yet, because of its low effective income tax rates, it requires a lower labor time in the US for low-skill workers to get out of poverty than in France and Belgium. In spite of the low effective income tax rate in Greece, working even full-time does not allow low-skill people to get out of poverty.

\section{Concluding remarks}

In this paper, we have proposed a normative property to make social preferences sensitive to poverty in a way that is compatible with the Pareto criterion. From that property, we have built social preferences, from which we have derived a simple criterion to evaluate tax schemes. This criterion has then been applied to analyze tax schemes in Europe and the US. One of the main achievements of this paper is indeed to have been able to go in a consistent way from an abstract property of social preferences to propositions of reforms for existing income tax systems.

Our application has been developed by considering households that benefit from all the policies we have contemplated. Given that some policies that are part of the fiscal system do not have a full take-up rate, other households do actually live below the budget curves that we have drawn. We consider that our approach is the correct one, though. Indeed, we should distinguish between the evaluation of a tax system dedicated to be applied to all households and the observation that there is room for increasing the take-up rate. Understanding the causes for non take-up is a very important, though different, research topic (see, for instance, Currie, 2004, for an excellent survey of the research on this topic).

A given tax system could yield two different income distributions, if applied to two different economies. The social preferences we define in this paper, however, would be said to be equally satisfied in these two economies. Indeed, under the assumption that agents choose their best possible bundle, our criterion only depends on the opportunities they are given by the tax system, not on the specific choices they make when facing these opportunities (provided, of course, assumption 1 in section 4 is satisfied). This is in sharp contrast to evaluating the ability of tax-transfer systems to alleviate poverty on the basis of the statistical distribution of incomes. We consider this an advantage of our approach, which clearly distinguishes between the design of the policy and the way agents react to it. Two systems offering the same opportunities to agents should receive the same praise and blame, independently of agents' choices.

The criterion we have defined evaluates an entire tax scheme on the basis 
of a single point. That implies that among suboptimal allocations, groups of socially indifferent allocations are likely to be large. This suggests using complementary criteria to discriminate among these groups. We did not investigate that question here, but it seems natural to us, in case two allocations are deemed socially indifferent, to look at the pre-tax income necessary to reach a consumption level just below the poverty line, and so on in case of further indifference.

We have presented above the derivation of a simple evaluation criterion for tax schemes from social preferences. It is important to note that this exercise did not require the detour through the derivation of a formula describing the optimal tax-transfer system, the kind of formula on which the literature in the field has devoted its largest effort so far. Maybe this calls for a change of focus of the literature towards the properties underlying the objectives of tax systems. The normative property we have studied in this paper is quite a natural one but certainly not the only one worth investigating, even if one concentrates on poverty alleviation.

\section{References}

[1] Atkinson, A.B. and J. Stiglitz 1976, "The design of tax structure: direct versus indirect taxation", Journal of Public Economics 6, 55-75.

[2] Besley, T. and S. Coate 1992, "Workfare versus welfare: incentive arguments for work requirements in poverty alleviation programs", American Economic Review 82, 249-261.

[3] Boadway, R. and. M. Keen 2000, "Redistribution", in Atkinson, A.B. and F. Bourguignon (eds.), Handbook of Income Distribution, vol. 1, Amsterdam: North-Holland.

[4] Citro, C.F. and R.T. Michael (eds.) 1995, Measuring Poverty: A New Approach, Washington, D.C.: National Academy Press.

[5] Currie, J. 2004, "The take-up of social benefits", NBER Working Paper 10448.

[6] Decancq, K., Fleurbaey, M. and F. Maniquet 2015, "Multidimensional poverty measurement with individual preferences", CORE Discussion Paper 2015/8.

[7] Dalton, H. 1920, "The measurement of the inequality of incomes", Economic Journal, 30, 348-361. 
[8] Diamond P. 1998, "Optimal income taxation: an example with a Ushaped pattern of optimal marginal tax rates", American Economic Review, 88(1), 83-95.

[9] Fleurbaey M. and F. Maniquet 2006, "Fair income tax", Review of Economic Studies, 73, 55-83.

[10] Fleurbaey, M. and F. Maniquet 2011, A Theory of Fairness and Social Welfare, Econometric Society Monograph, Cambridge: Cambridge University Press.

[11] Foster J., Greer, J. and E. Thorbecke 1984, "A class of decomposable poverty measures", Econometrica, 52, 761-766.

[12] Hausmann, D.M. 2012, Preferences, Value, Choice, and Welfare, Cambridge: Cambridge University Press.

[13] Iceland, J. 2005, Experimental Poverty Measures: Summary of a Workshop, National Research Council, Washington, D.C.: National Academy Press.

[14] Kanbur, R. and M. Keen 1989, "Poverty, incentives and linear income taxation", in: Dilnot, A. and I. Walker (eds.), The Economics of Social Security, Oxford: Clarendon Press.

[15] Kanbur, R. Keen, M. and M. Tuomala 1994a, "Optimal non-linear income taxation for the alleviation of income-poverty," European Economic Review, 38, 1613-1632.

[16] Kanbur, R. Keen, M. and M. Tuomala 1994b, "Labor supply and targeting in poverty alleviation programs", The World Bank Economic Review, 8, 191-211.

[17] Kanbur, R., Pirttilä, J., Tuomala, M. and T. Ylinen 2015, "Optimal taxation and public provision for poverty reduction", CEPR Discussion Paper No. 10754.

[18] Jacquet, L. and E. Lehmann 2015, "Optimal income taxation when skills and behavioral elasticities are heterogeneous", CESifo Working Paper 5265 .

[19] Maniquet, F. and Y. Sprumont 2004, "Fair production and allocation of a non-rival good", Econometrica, 72, 627-640. 
[20] Meyer, B.D. and J.X. Sullivan 2012, "Identifying the disadvantaged: official poverty, consumption poverty, and the new supplemental poverty measure", Journal of Economic Perspectives, 26(3), 111-136.

[21] Mirrlees, J. 1971, "An exploration in the theory of optimum income taxation", Review of Economic Studies, 38, 175-208.

[22] Pazner, E. 1979, "Equity, nonfeasible alternatives and social choice: a reconsideration of the concept of social welfare", in J.J. Laffont (ed.), Aggregation and Revelation of Preferences, Amsterdam: North-Holland.

[23] Pigou, A.C. 1912, Wealth and Welfare, London: Macmillan.

[24] Pirttila, J. and M. Tuomala 2004, "Poverty alleviation and tax policy," European Economic Review, 48, 1075-1090.

[25] Samuelson, P.A. 1974, "Complementarity: An essay on the 40th anniversary of the Hicks-Allen revolution in demand theory", Journal of Economic Literature, 12, 1255-1289.

[26] Samuelson, P.A. 1977, "Reaffirming the existence of 'reasonable' Bergson-Samuelson social welfare functions", Economica, 44, 81-88.

[27] Samuelson P.A. and S. Swamy 1974, "Invariant economic index numbers and canonical duality: survey and synthesis", American Economic Review, 64, 566-593.

[28] Short, K. 2014, "The supplemental poverty measure: 2013", United States Census Bureau, Current Population Reports, October 2014.

[29] Stiglitz, J.E. 1987, "Pareto efficient and optimal taxation and the New New Welfare Economics", in Auerbach, A.J. and M. Feldstein (eds.), Handbook of Public Economics, vol. 2, Amsterdam: North-Holland.

[30] Wane, W. 2001, "The optimal income tax when poverty is a public bad", Journal of Public Economics, 82, 271-299. 